\title{
Effectiveness of a Behavior Change Communication Intervention to Improve Knowledge and Perceptions About Abortion in Bihar and Jharkhand, India
}

By Sushanta K. Banerjee, Kathryn L. Andersen, Janardan Warvadekar and Erin Pearson

Sushanta K. Banerjee is senior research and evaluation advisor, and Janardan Warvadekar is research coordinator, both at Ipas India, New Delhi.

Kathryn L. Andersen is senior research and evaluation associate, and Erin Pearson is research and evaluation associate, both at Ipas, Chapel Hill, NC,

USA.

\begin{abstract}
CONTEXT: Although abortion became legal in India in 1971, many women are unaware of the law. Behavior change communication interventions may be an effective way to promote awareness of the law and change knowledge of and perceptions about abortion, particularly in settings in which abortion is stigmatized.
\end{abstract}

METHODS: To evaluate the effectiveness of a behavior change communication intervention to improve women's knowledge about India's abortion law and their perceptions about abortion, a quasi-experimental study was conducted in intervention and comparison districts in Bihar and Jharkhand. Household surveys were administered at baseline in 2008 and at follow-up in 2010 to independent, randomly selected cross-sectional samples of rural married women aged 15-49. Logistic regression difference-in-differences models were used to assess program effectiveness.

RESULTS: Analysis demonstrated program effectiveness in improving awareness and perceptions about abortion. The changes in the odds of knowing that abortion is legal and where to obtain safe abortion services were larger between baseline and follow-up in the intervention districts than the changes in odds observed in the comparison districts (odds ratios, 16.1 and 1.9, respectively). Similarly, the increase in women's perception of greater social support for abortion within their families and the increase in perceived self-efficacy with respect to family planning and abortion between baseline and follow-up was greater in the intervention districts than in the comparison districts (coefficients, 0.17 and 0.18 , respectively).

CONCLUSIONS: Behavior change communication interventions can be effective in improving knowledge of and perceptions about abortion in settings in which lack of accurate knowledge hinders women's access to safe abortion services. Multiple approaches should be used when attempting to improve knowledge and perceptions about stigmatized health issues such as abortion.

International Perspectives on Sexual and Reproductive Health, 2013, 39(3):142-151, doi: 10.1363/3914213

High rates of maternal death from unsafe abortion persist in India despite passage of the Medical Termination of Pregnancy (MTP) Act in 1971. ${ }^{1}$ This relatively liberal law permits a woman to obtain abortion services from a registered medical practitioner at any approved facility for many indications: to save her life, to preserve her physical and mental health, for economic or social reasons, in cases of rape or incest, when fetal impairment has been determined or, for married women, when pregnancy results from contraceptive failure. Amendments to the MTP Act in 2002 and 2003 aimed to expand access to safe abortion services by decentralizing abortion service regulation, including the monitoring of service delivery and the accreditation of private facilities providing first-trimester abortions; the amendments also allowed for delivery of medication abortion drugs by trained providers working in facilities not approved for surgical abortion. ${ }^{2}$

Forty years after the passage of the law, many women in India still seek abortion care from unqualified providers and die from unsafe abortion. Of the 6.4 million abortions performed every year in India, an estimated 3.6 million $(56 \%)$ are unsafe. ${ }^{3}$ It is estimated that $8-9 \%$ of maternal deaths are due to abortion-related complications, ${ }^{1}$ and almost 10,000 abortion-related deaths occur each year in India. ${ }^{4}$ Public health facilities are certified to provide abortion services; however, rural women may not use facilities with trained and certified providers because of difficulties reaching facilities ${ }^{5}$ or lack of awareness of the legality of abortion or the availability of services and providers. ${ }^{6,7}$ On average, there are only 10 certified abortion facilities per one million population in India, ${ }^{8}$ and one trained medical doctor per 224,000 rural population. ${ }^{6}$ In addition, many women are not aware that abortion is legal and available at government facilities, or do not know which facilities are certified by the government to provide abortion services. ${ }^{5}$

It may be possible to improve women's knowledge of and access to legal abortion services through behavior change communication interventions. Behavior change communication interventions have been used in many different areas of public health and with varied populations, ${ }^{9}$ and the scale of these interventions ranges from one-toone communication to mass media campaigns. Behavior change communication interventions have successfully been used in India to increase knowledge of contracep- 
tive use, immunization, and HIV and AIDS. ${ }^{10-12}$ According to an evaluation of the PRACHAR project in Bihar, the behavior change communication intervention was able to improve knowledge of and attitudes toward contraceptive use and increase demand for and use of contraceptives among young married couples. ${ }^{10}$ Similarly, an evaluation of a mass media entertainment education campaign on HIV and AIDS in New Delhi, Rajasthan and Uttar Pradesh found improvements in knowledge of and communication about HIV and AIDS. ${ }^{12}$

Behavior change communication has rarely been used in developing country contexts to promote healthy behaviors related to abortion, and most public communication campaigns on abortion are politically motivated. ${ }^{13}$ In the few formal evaluations of behavior change communication interventions on abortion that have been conducted, evidence from campaigns in India ${ }^{14,15}$ and Ghana ${ }^{16}$ to increase community awareness of safe abortion and post-abortion care suggests that these types of community-based education campaigns can be effective in increasing use of these services.

The most important elements of a successful behavior change communication campaign are well-designed messages that are administered frequently enough to be remembered. ${ }^{17}$ Studies in multiple settings have shown evidence of a dose-response relationship between exposure to behavior change communication messages and changes in knowledge, attitudes and practices. ${ }^{18-21}$ A study in Tanzania found that women who reported exposure to six media sources of family planning messages had odds of using family planning that were 11 times those of women who were not exposed, while women who were exposed to one source only were twice as likely to use family planning as women who were not exposed. ${ }^{18}$ A study in Zimbabwe found that youth who had been exposed to 5-8 components of an HIV and AIDS campaign were more likely to discuss AIDS with others or to seek care at a health center than youth who had been exposed to only 1-2 or 3-4 components of the campaign, after social and demographic factors and access to media were accounted for. ${ }^{19}$

To address the gap that currently exists between the availability of safe abortion services and their use, Ipas India, in coordination with the state governments of Bihar and Jharkhand, chose one district in each state (Patna and Lohardaga, respectively) as sites for a behavior change intervention. Not only are Bihar and Jharkhand two of the poorest and most socially disadvantaged states with some of the worst health outcomes in India, but both tribal and nontribal communities in these states have beliefs and misperceptions about abortion that act as barriers to accessing safe abortion services.

\section{The Intervention}

The intervention aimed to increase awareness about abortion legality and availability of services, as well as to change negative perceptions about abortion, through a community-level behavior change communication cam- paign. Implemented in 2008-2009, the campaign provided information on the legality of abortion, the locations of the nearest public-sector facilities offering safe abortion and contraceptive services, and the health consequences of unsafe abortion using a fictitious young woman named Kalyani (which means auspicious) as the protagonist. The intervention used a variety of approaches to engage and inform the community. Interpersonal communication activities included both one-on-one interactions with health educators and community group meetings. These activities were intended to provide women with information and an opportunity to ask questions in a household setting. Street dramas were performed in central locations within the villages with the goal of exposing the full community to the issue of abortion. Actors for the dramas were selected from the villages, and the scripts were pretested in the community so that locally relevant dialects and terminology could be incorporated. The purpose of this strategy was twofold: so that village members would perceive the intervention as specific to their own community and culture rather than generic to any setting, thereby improving acceptance and interest, and so that the actors could continue to share information about abortion even after the intervention. At the end of each show, an interactive quiz was conducted to reinforce the message and promote comprehension. Wall signs were placed in central locations in the villages and provided key information on the legality and availability of safe abortion services in public facilities. The intervention staff also distributed low-literacy reference materials in the community.

These intervention activities were designed to promote self-efficacy in reproductive health. The Kalyani campaign tells the story of a woman who confidently approaches a provider about safe abortion services and other sexual and reproductive health issues with basic knowledge of India's abortion law and her rights to obtain these services. The interpersonal communication activities were intended to work at the individual level, empowering women and improving their confidence that they could obtain reproductive health services such as abortion. The wall signs and street dramas were designed to work at the community level to normalize abortion and promote social support among family and community members for women's rights to receive these services.

Intervention activities were tailored to the baseline characteristics and media use of the target audience, women aged 15-49 years. ${ }^{22}$ Given the low literacy level in the target audience, communication materials were developed using local dialects and were pilot tested in the intervention communities through focus group discussions and indepth interviews. Intervention activities were implemented by three local nongovernmental organizations.

During the study period, public-sector facilities in both intervention and comparison districts received the standard Ipas facility-level intervention. ${ }^{23,24}$ The intervention included training the medical doctors in the provision of safe abortion services and the nursing staff in instrument 
processing, infection control procedures and postabortion contraceptive counseling. Facilities also received posters to inform patients that safe abortion services were available in the facility. All facilities offered manual or electric vacuum aspiration, and some provided medication abortion using mifepristone followed by misoprostol.

\section{METHODS}

The present study aimed to determine which characteristics of women were associated with exposure to the behavior change communication intervention. The study was also designed to evaluate the effectiveness of the intervention in improving abortion-related awareness, knowledge and perceptions, including social support from family, social norms in the community, self-efficacy regarding family planning and abortion, and perceived health risks of unsafe abortion.

\section{Study Design and Sample}

The evaluation used a pre-post quasi-experimental research design. Two districts (Saran in Bihar and Gumla in Jharkhand) were chosen in consultation with the state governments to serve as comparison districts because they had social and demographic characteristics similar to those in Patna and Lohardaga, the intervention districts (Table 1). All four districts were purposively selected on the basis of the availability of doctors trained in the provision of safe abortion services. The intervention sites were chosen because they had the most trained safe providers in their respective states. In all four districts, additional providers were trained throughout the course of the study.

To minimize contamination, the districts selected for this evaluation are far from one another. The two intervention districts are more than $100 \mathrm{~km}$ from one another, and the comparison districts are at least $40 \mathrm{~km}$ from the intervention districts. Surveys were administered to independent, cross-sectional samples of women in the intervention and comparison districts in 2008 at baseline, prior to implementation, and once again at follow-up in 2010 after the intervention activities had been conducted in the intervention districts. The sampling frame for this study included only rural blocks of the selected intervention and comparison districts. The urban blocks were not included

\begin{tabular}{|c|c|c|c|c|}
\hline \multirow[t]{2}{*}{ Characteristic } & \multicolumn{2}{|l|}{ Bihar } & \multicolumn{2}{|l|}{ Jharkhand } \\
\hline & $\begin{array}{l}\text { Patna } \\
\text { (Intervention) }\end{array}$ & $\begin{array}{l}\text { Sarna } \\
\text { (Comparison) }\end{array}$ & $\begin{array}{l}\text { Lohardaga } \\
\text { (Intervention) }\end{array}$ & $\begin{array}{l}\text { Gumla } \\
\text { (Comparison) }\end{array}$ \\
\hline Scheduled caste & 19.6 & 12.2 & 3.5 & 5.0 \\
\hline Scheduled tribe & 0.7 & 0.2 & 60.3 & 70.2 \\
\hline Literacy (general) & 51.4 & 50.1 & 39.0 & 40.5 \\
\hline Literacy (female) & 13.8 & 13.4 & 27.3 & 30.8 \\
\hline $\begin{array}{l}\text { Working in nonagricultural } \\
\text { activity }\end{array}$ & 20.9 & 22.3 & 46.1 & 41.3 \\
\hline
\end{tabular}

Source: Registrar General, India, Census of India, New Delhi: Government of India, 2001. Note: Figures are percentages. in the sampling frame because this intervention was carried out only in rural areas. As a result, the baseline and follow-up samples were not representative of the districts as a whole, but they were representative of the rural population in the study districts.

Two-stage stratified random sampling was used to select women from this population. In the first stage, 18 villages from each of the four districts, 72 in all, were selected, with probability proportional to size. Then, a detailed household listing was carried out in each selected village to generate the universe of households with eligible women. A household was defined as a person or group of persons staying together under the same roof and sharing food from the same kitchen. Women were eligible to participate in the study if they were married and aged 15-49. Women were excluded if they had been relying on female or male sterilization for contraception for more than three years. Twenty households with eligible women were chosen from each selected village using systematic random sampling. Only one woman was selected from each household, and in households with more than one eligible woman, the Kish table was used to select a study participant.

Women enrolled in the study participated in a survey administered by an interviewer at baseline and follow-up that collected data on social and demographic characteristics, sources of reproductive health information, healthseeking behaviors, knowledge of and perceptions about abortion, and reproductive histories. Women reporting an abortion in the previous three years were administered an additional module on their last abortion experience. This module included questions about the abortion information she received from providers or other actors, the type of abortion provider and procedure, and any complications experienced. The surveys were administered by trained local investigators from an external data collection agency and took 40-80 minutes to complete. A total of 1,411 and 1,441 women were successfully surveyed at baseline and follow-up, respectively.* Informed consent was obtained from all participants prior to enrollment. Because this was a low-literacy population, the statement of consent was read to the women, who then provided verbal consent or a signature if possible. To protect the participants' privacy, interviewers requested privacy from other household members who tried to intervene or listen in. If privacy could not be ensured, the interview was postponed and rescheduled. The overall response rate for the study was $97 \%$ at baseline and $99 \%$ at follow-up. This study underwent ethical review and was approved by the institutional review board of the Centre for Media Studies in New Delhi.

\section{Measures}

The outcome measures assessed in this study at baseline and follow-up included knowledge of and perceptions about abortion. Knowledge questions covered such top-

*There was little to no overlap between the baseline and follow-up samples because the villages sampled at those two points were different. 
ics as the legal status of abortion in India, knowledge of any abortion method and sources of safe abortion services. Women were asked whether abortion is legal in India, and they were also asked to spontaneously provide the legal gestational age limit for abortion. Women were asked whether they knew about any abortion method, and if so, to name the methods they knew. Knowledge about a source of safe abortion services was assessed by asking women where they would advise a friend or relative to go for abortion services; accurate knowledge was defined as listing a legal abortion provider type or location. Responses to knowledge items were dichotomized into accurate or inaccurate knowledge.

Data on perceptions about abortion were collected using a five-point Likert scale, ranging from "strongly disagree" to "strongly agree." Women were asked a series of questions on their perceptions about availability of services, social norms regarding abortion, social support, self-efficacy and health risks associated with unsafe abortion. Availability of services was assessed by asking women to respond to such statements as "We do not have any option to get abortion services at a facility close to our village" and "Abortion services are normally available at urban-based private clinics/nursing homes." Social norms were assessed by asking women to respond to such statements as "In my community, it is not acceptable to talk about any abortion-related issue" and "Couples who want to terminate an unwanted pregnancy would likely approach a provider who respects confidentiality." Social support was measured using such statements as "If I were to go for an abortion, my family would support me" and "If I need to go for an abortion, I would have to do so without telling anyone." Self-efficacy was measured using a series of statements such as "I am confident I can personally decide when I want to have children" and "I can confidently talk to a medical doctor about issues related to abortion." Perceptions of health risks associated with unsafe abortion were measured using such statements as "Women may suffer with severe complications if abortions are carried out by untrained providers" and "There is a risk to the mother's health if abortion is done at a mature stage of pregnancy."

For perceptions about abortion, scale scores were computed by summing the five-point Likert scale scores across items and dividing by the number of items, which provided standardized mean scores ranging from 1 to 5. Negative responses were reverse-coded so that a higher mean score indicates a more positive attitude. The scaled scores had values for Cronbach's alpha ranging from 0.28 for the scale on perceived social norms to 0.56 for the scale on perceived health risks of unsafe abortion. ${ }^{22}$

At baseline and follow-up, women were asked whether they had received any abortion-related information and to spontaneously report the sources of abortion information. At follow-up, exposure to the intervention was assessed separately for each intervention activity. If a woman reported seeing or participating in a communication event, she was asked to recall the message of the event. In addition, the number of message formats (interpersonal communication, street drama or wall signs) to which a woman was exposed was assessed, ranging from 0 to 3 . For example, if a woman reported seeing a wall sign and attending a street drama, she was exposed to two message formats.

\section{Analysis}

Because the sampled districts of Bihar and Jharkhand had similar social and demographic profiles, the districts were pooled across states into one intervention group and one comparison group. Descriptive data are presented that compare changes over time (pre- and postintervention) in intervention and comparison districts on social and demographic characteristics. Changes between baseline and follow-up surveys were assessed using chi-square tests. This analysis shows that significant differences exist

\begin{tabular}{|c|c|c|c|c|}
\hline \multirow[t]{2}{*}{ Characteristic } & \multicolumn{2}{|l|}{ Intervention } & \multicolumn{2}{|l|}{ Comparison } \\
\hline & $\begin{array}{l}\text { Baseline } \\
(\mathrm{N}=702)\end{array}$ & $\begin{array}{l}\text { Follow-up } \\
(\mathrm{N}=721)\end{array}$ & $\begin{array}{l}\text { Baseline } \\
(\mathrm{N}=709)\end{array}$ & $\begin{array}{l}\text { Follow-up } \\
(\mathrm{N}=720)\end{array}$ \\
\hline \multicolumn{5}{|c|}{$\begin{array}{l}\text { PERCENTAGE DISTRIBUTIONS } \\
\text { Age }\end{array}$} \\
\hline$<25$ & 22.8 & $34.7^{* * *}$ & 19.9 & $35.8^{* * *}$ \\
\hline$\geq 25$ & 77.2 & $65.3^{* * *}$ & 80.1 & $64.2^{* * *}$ \\
\hline \multicolumn{5}{|l|}{ Education } \\
\hline None & 64.5 & 57.6 & 59.2 & 55.1 \\
\hline Primary & 4.7 & 9.6 & 3.1 & $7.1^{* * *}$ \\
\hline Middle & 19.1 & 21.9 & 25.0 & 25.7 \\
\hline Secondary & 7.4 & 7.9 & 8.5 & 6.9 \\
\hline >secondary & 4.3 & 3.1 & 4.2 & 5.1 \\
\hline \multicolumn{5}{|l|}{ Religion } \\
\hline Hindu & 56.4 & 58.0 & 66.2 & 70.0 \\
\hline Muslim & 11.7 & 12.2 & 9.9 & $5.3^{* * *}$ \\
\hline Christian & 4.4 & 3.7 & 7.9 & 7.2 \\
\hline Sarna & 27.5 & 26.1 & 16.0 & 17.5 \\
\hline \multicolumn{5}{|l|}{ Caste } \\
\hline General caste & 10.4 & 10.1 & 13.5 & $18.3^{* *}$ \\
\hline Scheduled caste & 9.1 & $14.0 * * *$ & 7.6 & 10.4 \\
\hline Scheduled tribe & 34.2 & 32.3 & 29.2 & 26.9 \\
\hline Other backward class & 46.3 & 43.6 & 49.6 & 44.3 \\
\hline \multicolumn{5}{|l|}{ Family type } \\
\hline Nuclear & 47.2 & 48.1 & 40.9 & 43.3 \\
\hline Joint/extended & 52.8 & 51.9 & 59.1 & 56.7 \\
\hline \multicolumn{5}{|l|}{ Wealth index } \\
\hline Low & 82.9 & $70.2^{* *}$ & 83.4 & $74.7^{* * *}$ \\
\hline Medium & 12.3 & $21.5^{* * *}$ & 11.6 & $19.6^{* * *}$ \\
\hline High & 4.8 & $8.3^{* * *}$ & 5.1 & 5.7 \\
\hline \multicolumn{5}{|l|}{ Mass media exposure } \\
\hline Yes & 28.5 & $43.8^{* * *}$ & 24.3 & $40.4^{* * *}$ \\
\hline No & 71.5 & $56.2^{* * *}$ & 75.7 & $59.6^{* * *}$ \\
\hline Total & 100.0 & 100.0 & 100.0 & 100.0 \\
\hline \multicolumn{5}{|l|}{ MEANS } \\
\hline Age (in yrs.) & $28.9(6.0)$ & $27.8(6.5)^{* * *}$ & $29.4(6.0)$ & $28.1(6.9)^{* * *}$ \\
\hline Schooling & $2.9(4.2)$ & $3.0(4.0)^{* * *}$ & $3.3(4.4)$ & $3.5(4.3)^{* * *}$ \\
\hline Wealth score & $3.8(3.7)$ & $5.3(4.4)^{* * *}$ & $3.7(3.8)$ & $4.9(3.7)^{* * *}$ \\
\hline
\end{tabular}

*Difference from baseline significant at $\mathrm{p} \leq .05$. ${ }^{* *}$ Difference from baseline significant at $\mathrm{p} \leq 01$. ${ }^{* * *}$ Difference from baseline significant at $\mathrm{p} \leq .001$. Notes: Figures in parentheses are standard deviations. Percentages may not total 100.0 because of rounding. 
TABLE 3. Adjusted odds ratios (and 95\% confidence intervals) from logistic regression analyses identifying associations between selected social and demographic characteristics and exposure to campaign messages in intervention districts at follow-up, by type of message

\begin{tabular}{|c|c|c|c|c|}
\hline Characteristic & $\begin{array}{l}\text { Any activity } \\
(\mathrm{N}=721)\end{array}$ & $\begin{array}{l}\text { Interpersonal } \\
\text { communication } \\
(\mathrm{N}=721)\end{array}$ & $\begin{array}{l}\text { Street drama } \\
(\mathrm{N}=721)\end{array}$ & $\begin{array}{l}\text { Wall sign } \\
\text { or poster } \\
(\mathrm{N}=721)\end{array}$ \\
\hline \multicolumn{5}{|l|}{ Age } \\
\hline$<25$ (ref) & 1.0 & 1.0 & 1.0 & 1.0 \\
\hline$\geq 25$ & $1.5(1.0-2.1)^{*}$ & $1.7(1.0-2.6)^{*}$ & $1.2(0.8-1.9)$ & $1.3(0.9-1.9)$ \\
\hline \multicolumn{5}{|l|}{ Education } \\
\hline None (ref) & 1.0 & 1.0 & 1.0 & 1.0 \\
\hline Primary & $3.2(1.9-5.6)^{* * * *}$ & $2.9(1.5-5.4)^{* * *}$ & $1.8(0.9-3.5)$ & $2.8(1.6-4.7)^{* * *}$ \\
\hline Middle & $2.6(1.7-3.9)^{* * * *}$ & $2.0(1.2-3.3)^{* *}$ & $2.2(1.3-3.6)^{* * *}$ & $2.5(1.6-3.7)^{* * * *}$ \\
\hline Secondary & $2.3(1.2-4.3)^{* *}$ & $1.1(0.4-2.8)$ & $1.3(0.6-3.3)$ & $2.6(1.4-4.8)^{* *}$ \\
\hline >secondary & $4.1(1.5-10.9)^{* *}$ & $2.7(0.9-8.0)$ & $2.7(0.9-7.9)$ & $5.3(2.0-14.1)^{* * *}$ \\
\hline \multicolumn{5}{|l|}{ Religion } \\
\hline Hindu (ref) & 1.0 & 1.0 & 1.0 & 1.0 \\
\hline Muslim & $2.3(1.4-3.9)^{* * * *}$ & $1.4(0.7-2.8)$ & $2.3(1.2-4.4)^{*}$ & $1.9(1.1-3.1)^{*}$ \\
\hline Christian & $2.0(0.6-7.3)$ & $1.4(0.3-5.5)$ & $0.5(0.1-1.7)$ & $1.7(0.5-5.7)$ \\
\hline Sarna & $0.8(0.3-2.1)$ & $1.5(0.5-4.5)$ & $0.6(0.2-1.4)$ & $0.8(0.3-1.9)$ \\
\hline \multicolumn{5}{|l|}{ Caste } \\
\hline General caste (ref) & 1.0 & 1.0 & 1.0 & 1.0 \\
\hline Scheduled caste & $2.5(1.3-5.0)^{* *}$ & $4.2(1.5-12.1)^{* *}$ & $1.7(0.6-4.8)$ & $2.1(1.1-4.3)^{*}$ \\
\hline Scheduled tribe & $3.4(1.2-9.7)^{*}$ & $3.0(0.7-12.4)$ & $6.5(1.9-22.0)^{* *}$ & $2.3(0.8-6.5)$ \\
\hline Other backward class & $1.1(0.6-1.9)$ & $2.0(0.8-5.1)$ & $1.2(0.5-2.8)$ & $1.0(0.5-1.7)$ \\
\hline \multicolumn{5}{|l|}{ Family type } \\
\hline Nuclear (ref) & 1.0 & 1.0 & 1.0 & 1.0 \\
\hline Joint/extended & $0.8(0.6-1.2)$ & $0.8(0.5-1.3)$ & $0.6(0.4-1.0)^{*}$ & $1.0(0.7-1.4)$ \\
\hline \multicolumn{5}{|l|}{ Wealth index } \\
\hline Low (ref) & 1.0 & 1.0 & 1.0 & 1.0 \\
\hline Medium & $1.2(0.8-1.8)$ & $1.2(0.7-2.0)$ & $1.2(0.7-2.0)$ & $1.3(0.8-1.9)$ \\
\hline High & $1.2(0.6-2.4)$ & $1.3(0.6-3.3)$ & $0.9(0.3-2.3)$ & $1.2(0.6-2.4)$ \\
\hline -2 log likelihood & 905.7 & 614.2 & 617.9 & 889.0 \\
\hline
\end{tabular}

${ }^{*} \mathrm{p}<.05 .{ }^{* *} \mathrm{p}<.01 .{ }^{* * *} \mathrm{p}<.001$. Notes: Models adjust for women's age, education, caste, family type and wealth. ref=reference group.
To assess program effectiveness, logistic and linear regression models using difference-in-differences estimation were used; all models adjusted for key social and demographic characteristics. Difference-in-differences estimation compares the changes in key outcomes between baseline and follow-up in the intervention and comparison districts to provide evidence of program effectiveness. ${ }^{25}$ Differencein-differences can be used with quasi-experimental study designs by pooling independent cross-sections across time and using the change in outcomes for the comparison districts as a proxy for the change in outcomes that would have been observed in the intervention districts in the absence of the intervention. ${ }^{25,26}$

To evaluate the dichotomized knowledge outcomes, logistic regression models using difference-in-differences estimation were used. Perceptions about abortion were analyzed as continuous variables, and linear regression models using difference-in-differences estimation were employed to evaluate these outcomes.

\section{RESULTS}

The social and demographic characteristics of the pooled respondents in intervention districts were generally similar to those of the respondents in the comparison districts at baseline and at follow-up (Table 2, page 145). Although age, education, wealth and exposure to mass media differed between the intervention and comparison districts, these differences were consistent between baseline and follow-up. Most women were aged 25 years or older (64-80\%), had never attended school (55-65\%), lived in a joint or extended household (52-59\%) and had a low standard of living (70-83\%). According to the Government of India's caste designations, ${ }^{*}$ most respondents were from scheduled tribes (27-34\%) or other backward classes (44-50\%). There were some differences in religion between the intervention and comparison districts with the comparison districts having more Hindus (66-70\% vs. $56-58 \%$ ) and Christians ( $7-8 \%$ vs. $4 \%$ ), and the intervention districts having more women who identified as Muslim (12\% vs. $5-10 \%$ ) or Sarna (26-28\% vs. $16-18 \%$ ).

\section{Abortion Information}

This section reports on intervention exposure and knowledge of abortion. Because significant differences exist between the baseline and follow-up samples, as noted in Table 2, these unadjusted percentages are not comparable. In the intervention districts, the percentage of women who reported having received information on abortion was $15 \%$ at baseline and $50 \%$ at follow-up (not shown). In the comparison districts, those percentages were 10\% and 3\%, respectively. At follow-up, women in the intervention districts reported receiving information through wall signs (38\%), street dramas (17\%) and community group or one-to-one meetings (17\%). However, $55 \%$ women in the intervention districts and 99\% of women in the comparison districts reported at follow-up that they had not been exposed to the Kalyani campaign. 
Among women in the intervention districts who reported exposure to a message on abortion (not shown), the most common messages that women recalled at follow-up were that early abortion is safe for a woman (59\%), that abortion services are available at public facilities (40\%) and that abortion is legal in India (22\%). Other messages, such as the legal gestational limit for abortion, were recalled by very few women in the intervention districts at follow-up. Among women who reported having received information on abortion, the majority (79\%) in the intervention districts recalled at least one correct message at follow-up; only 3\% had recalled an accurate message at baseline. In the comparison districts, just $1 \%$ of women could recall an accurate message about abortion at baseline; at follow-up, $20 \%$ of women could.

\section{Women's Characteristics and Intervention Exposure}

Women aged 25 or older had significantly higher odds than younger women of exposure to an intervention activity (odds ratio, 1.5-Table 3). Older women also had higher odds of having participated in community group or one-to-one meetings (1.7); no differences by age were seen in exposure to any other activity. Significant differences in exposure to any intervention activity were observed by educational level. Compared with women with no education, women at every educational level had increased odds of exposure; for example, the odds of exposure to any activity for women with more than a secondary education were four times as high as the odds for women with no education (4.1). A similar pattern was seen for exposure to wall signs or posters ( 5.3 for women with more than a secondary education).

Education was also associated with exposure to interpersonal communication. Women with a primary school education had odds of exposure to community group or one-to-one meetings almost three times as great as those for women with no education (odds ratio, 2.9), and women with a middle school education had odds of exposure twice as high as women with no education (2.0). Women with a middle school education were significantly more likely to have been exposed to a street drama than women with no education (2.2). Muslim women had higher odds than Hindu women of exposure to any activity (2.3), street dramas (2.3), and wall signs or posters (1.9). Compared with women in the general caste group, those in a scheduled caste or scheduled tribe had higher odds of exposure to any activity (2.5 and 3.4, respectively). Women in a scheduled caste were more likely than those in the general caste group to have been exposed to community group or one-to-one meetings (4.2), and to have been exposed to wall signs or posters (2.1). Women in a scheduled tribe had odds of exposure to a street drama more than six times those for women who were in the general caste group (6.5). Compared with women who lived in nuclear households, those who lived in joint or extended households (mostly with parents-in-law) had lower odds of exposure to street dramas (0.6).
TABLE 4. Adjusted odds ratios (and 95\% confidence intervals) from logistic regression analyses identifying associations between exposure to campaign messages reported at follow-up by women in intervention districts and abortion knowledge, by message content

\begin{tabular}{lccl}
$\begin{array}{l}\text { Level and type } \\
\text { of exposure }\end{array}$ & $\begin{array}{l}\text { Legal status of } \\
\text { abortion } \\
(\mathrm{N}=721)\end{array}$ & $\begin{array}{l}\text { Gestational age } \\
\text { limit for } \\
\text { abortion } \\
(\mathrm{N}=721)\end{array}$ & $\begin{array}{l}\text { Legal status } \\
\text { of abortion and } \\
\text { gestational age limit } \\
(\mathrm{N}=721)\end{array}$ \\
\hline $\begin{array}{l}\text { Any exposure } \\
\text { No (ref) }\end{array}$ & 1.0 & 1.0 & 1.0 \\
Yes & $3.1(2.1-4.5)^{* * *}$ & $7.1(2.7-19.0)^{* * *}$ & $6.7(2.5-18.0)^{* * *}$ \\
-2 log likelihood & 806.7 & 259.1 & 249.5 \\
No. of message formats exposed to & & \\
None (ref) & 1.0 & 1.0 & 1.0 \\
1 & $2.1(1.4-3.3)^{* * *}$ & $1.8(0.8-4.2)$ & $2.2(1.0-5.4)$ \\
2 & $4.5(2.5-8.3)^{* * *}$ & $2.1(0.8-5.4)$ & $2.6(1.0-7.1)$ \\
3 & $4.9(2.0-11.6)^{* * *}$ & $3.7(1.3-11.0)^{*}$ & $4.5(1.5-13.5)^{* *}$ \\
-2 log likelihood & 800.9 & 273.5 & 260.1 \\
& & & \\
Type of exposure & 1.0 & 1.0 & 1.0 \\
None (ref) & $4.2(2.3-7.9)^{* * *}$ & $1.3(0.6-3.0)$ & $1.4(0.6-3.2)$ \\
Interpersonal communication & $1.6(1.1-2.5)^{*}$ & $2.2(0.9-4.7)$ & $2.5(1.1-5.6)^{*}$ \\
Wall sign or poster & $1.3(0.8-2.3)$ & $1.1(0.5-2.6)$ & $1.1(0.4-2.4)$ \\
Street drama & 794.0 & 272.8 & 259.3 \\
-2 log likelihood & & & \\
\hline
\end{tabular}

${ }^{*} \mathrm{p}<.05 .{ }^{* *} \mathrm{p}<.01 .{ }^{* * *} \mathrm{p}<.001$. Notes: Models adjust for women's age, education, caste, family type and wealth ref=reference group.

\section{Abortion Knowledge and Intervention Exposure}

Women who had been exposed to any intervention communication event had significantly higher odds than those who had not of knowing the legal status of abortion (odds ratio, 3.1-Table 4), the legal gestational age limit for abortion (7.1) and both abortion's legal status and the gestational age limit (6.7) than women who had not been exposed to any intervention activities. The number of message formats to which a woman had been exposed was associated with increased odds of knowing the legal status of abortion. The odds of knowing the legal status of abortion among those who had been exposed to any one behavior change communication activity were twice the odds among women who had not been exposed (2.1). Women who had been exposed to two or three different message formats were even more likely than those with no exposure to know abortion's legal status (4.5 and 4.9, respectively). Women who had been exposed to all three message formats had higher odds than women with no exposure of knowing the legal gestational age limit for abortion (3.7) and of being aware of both the legal status

\section{TABLE 5. Odds ratios (and 95\% confidence intervals) from logistic regression analysis assessing the association be- tween campaign exposure and recall of at least one cor- rect message about abortion}

Exposure and number of formats

Odds ratio

\begin{tabular}{lc}
\hline Not exposed (ref) & 1.0 \\
Exposed to any & $1.5(0.7-3.3)$ \\
Exposed to 1 & $0.8(0.3-1.8)$ \\
Exposed to 2 & $5.0(1.7-14.8)^{* *}$ \\
Exposed to 3 & $17.6(2.1-147.8)^{* *}$ \\
\hline
\end{tabular}

**p<.01. Notes: Odds ratios are adjusted for women's age, education, caste, family type and wealth. ref=reference group. 
of abortion and the gestational age requirement (4.5). In addition, the type of exposure was related to awareness. Women who had been exposed to interpersonal communication were more likely to know the legal status of abortion than women who had not been exposed to any event (4.2). Likewise, women who had been exposed to wall signs were more likely than women who had not been exposed to any event to be aware of the legal status of abortion (1.6) and to know both the legal status of abortion and the gestational age limit (2.5).

Table 5 (page 147) shows results from multivariate analyses of the association between the number of message formats to which a woman had been exposed and recalling at least one correct message in the intervention districts. Though any exposure to an intervention communication event was not associated with recalling a correct message, the number of activities to which a woman was exposed was strongly associated with recall. Compared with women who had not been exposed, women who had been exposed to two activities had five times the odds of recalling a correct message (5.0), and those who had been exposed to all three activities had almost 18 times the odds of recalling a correct message (17.6).

\section{Intervention Effectiveness}

The results of the difference-in-differences regression analysis indicate that the behavior change communication program was associated with an increase in knowledge about abortion in the intervention districts between baseline and follow-up, compared with the change observed in the comparison districts (Table 6). Among women in the intervention districts, the increases between baseline and follow-up in the odds of knowing the legal status of abortion in India, of knowing the gestational age through which abortion is legal and of knowing where to obtain abortion services were significantly greater than the increases among women in the comparison districts (odds ratios of 16.1, 7.4 and 1.9 , respectively) after social and demographic characteristics were adjusted for. Compared with the increase among women in the comparison districts of the odds of

\begin{tabular}{lc} 
TABLE 6. Adjusted odds ratios and regression coefficients (and 95\% confidence inter- \\
vals) from difference-in-differences models evaluating the effectiveness of the inter- \\
vention in improving abortion knowledge and perceptions about abortion \\
Knowledge and perception & $\begin{array}{l}\text { Odds ratio or } \\
\text { coefficient }\end{array}$ \\
\hline Knowledge & $16.1(11.3-22.9)^{* * * *}$ \\
Legality of abortion & $7.4(1.4-39.7)^{*}$ \\
Gestational age limit & $1.9(1.4-2.6)^{* * * *}$ \\
Source of services & $14.9(9.1-24.5)^{* * * *}$ \\
Legality and source of services & $0.5(0.12-1.9)$ \\
Any surgical method & $1.1(0.7-1.6)$ \\
A medical method & \\
Perception & \\
Social support for abortion within family & $0.17(0.04-0.31)^{* *}$ \\
Social norms regarding abortion within community & $-0.22(-0.37 \text { to }-0.07)^{* *}$ \\
Self-efficacy with respect to family planning and abortion & $0.18(0.06-0.31)^{* * *}$ \\
Health risks associated with unsafe abortion & $0.01(-0.12-0.14)$
\end{tabular}

${ }^{*} \mathrm{p}<.05 .{ }^{* *} \mathrm{p}<.01 .{ }^{* * *} \mathrm{p}<.001 .{ }^{* * * *} \mathrm{p}<.0001$. Notes: Odds ratios and regression coefficients are adjusted for women's age, education, caste, family type and wealth. knowing both abortion's legal status and a source of abortion services, the increase in those odds among women in the intervention districts was almost 15 times as great (14.9). No difference was observed in knowledge about specific abortion methods.

There were also significant differences between the intervention and comparison districts in changes between baseline and follow-up in perceptions about abortion. Women in the intervention districts at follow-up reported higher perceived levels of social support for abortion within their families (coefficient, 0.17) and higher levels of self-efficacy with respect to family planning and abortion (0.18), after social and demographic characteristics were adjusted for. However, women in the intervention districts at follow-up reported lower perceived levels of support for abortion within their communities than did those in comparison districts (-0.22). There was no significant difference in perceptions about the health risks of unsafe abortion.

\section{DISCUSSION}

The purpose of this study was to assess the effectiveness of the Kalyani behavior change communication campaign to raise awareness among women in Bihar and Jharkhand about legal aspects and sources of safe abortion services. Over the two-year study period, the behavior change communication intervention was associated with improved knowledge about the legal aspects of abortion in India and about where to obtain safe abortion services. The difference-in-differences regression analysis showed improvements across all knowledge indicators, except for knowledge of specific methods of abortion, in the intervention group compared with the comparison group. In the adjusted difference-in-differences analysis, women in the intervention group were twice as likely as women in the comparison group to know a legal source of abortion services.

Both reported exposure to abortion messages and message recall improved significantly between baseline and follow-up among women in the intervention districts. Although the intervention was designed to reach all married women, a strong association was seen between certain social and demographic characteristics and program exposure. Married women who were younger than 25 and had no or little education were less likely to report exposure to the intervention than their older, more educated counterparts. In addition, women living in joint or extended family households were less likely to attend street dramas than women living in nuclear households. These findings indicate that more research is needed to understand how the intervention can be altered to reach these groups of women.

This study also found evidence that women benefit most from exposure to multiple message formats. Only women who were exposed to all three message formats had higher odds of accurate knowledge about abortion than women with no exposure to messages. However, relationships differed by the number of formats to which a woman was ex- 
posed and accurate knowledge, depending on the type of message. For example, women with any exposure to an intervention message had significantly higher odds of recalling that abortion is legal than their counterparts who had never been exposed to a message. However, only women who had been exposed to all three types of activities were significantly more likely than those exposed to none to accurately recall a more complex message, such as the gestational age limit for legal abortion. This finding suggests that to increase detailed knowledge about abortion in areas where levels of knowledge are low, it is important to ensure that women receive messages in multiple formats. This finding also has implications for campaign message development, particularly on the legal gestational age limit.

This intervention not only increased women's knowledge about abortion, but also improved their perceived self-efficacy with regard to family planning and abortion as well as women's perceived social support for abortion within their families. These findings are encouraging because we expect that increased knowledge and improved perceptions about abortion will be associated with a greater likelihood that women who want to terminate a pregnancy will seek safe abortion services.

Though women living in the intervention area at followup were more likely than those in the comparison districts to have greater knowledge about abortion and higher levels of perceived self-efficacy and perceived social support for abortion within their families, they were less likely to perceive favorable social norms regarding abortion in their communities. This finding may indicate that although the intervention increased awareness about abortion in the community, the increased attention to the issue may have led those with negative attitudes toward abortion to be more vocal. It is promising that perceived social support within the family increased despite perceptions of decreased social support within the community. Improvements in attitudes at the household level may occur more quickly than improvements at the community level, and a longer intervention may be required to find improvements at the community level. However, it is also possible that this finding is spurious because the scale for perceived social norms in the community had poor reliability.

\section{Study Limitations}

This study has several limitations. Because of the small number of women who had had an abortion within the previous three years, it was not possible to compare changes in use of legal abortion services in the intervention districts between baseline and follow-up with changes observed in the comparison districts using difference-indifferences analysis. Therefore, changes in knowledge and perceptions about abortion were used as outcome measures rather than changes in behavior, even though behavior change would have been a more informative outcome for this study. An additional limitation is the presence of differences in social and demographic characteristics such as age, education, wealth and exposure to mass media between baseline and follow-up in both the intervention and comparison districts. The source of these differences is unknown because the same sampling frame and random selection procedures were used at baseline and follow-up. Perhaps these differences are due to secular trends over the two-year follow-up period, or due to random variation between the villages selected at baseline and follow-up. Multivariate analyses were used to account for the differences between the baseline and follow-up samples. The findings of the difference-in-differences analysis are expected to be robust to the differences in the social and demographic profiles, as the magnitude of the changes over time was the same in intervention and comparison districts, and the models adjusted for these characteristics. Finally, the Cronbach's alpha scores for the abortion perception scales were relatively low (0.28 to 0.56$)$, suggesting that no items measured perceptions well. Further work needs to be done to create informative scales to understand abortion perceptions in these communities.

\section{Conclusions}

Behavior change communication interventions can be an effective means of improving knowledge of and perceptions about abortion in settings where myths, misperceptions and lack of information hinder women's access to safe abortion services. This study also provides evidence that exposure to multiple message formats matters. Women who were exposed to all three message formats-interpersonal communication, wall signs and street dramasshowed the greatest increases in knowledge, particularly in knowledge about more complex concepts such as the legal gestational age limit. Behavior change communication interventions should use multipronged approaches that act at the individual and community levels when attempting to improve knowledge and perceptions about stigmatized health issues such as abortion. This study also demonstrates that more interactive forms of communication, such as interpersonal communication, lead to greater increases in knowledge than more passive forms of communication. Future studies should link behavior change communication interventions with key health outcomes such as abortion-related morbidity and utilization of safe abortion services.

\section{REFERENCES}

1. Register General of India, Maternal Mortality in India 1997-2003: Trends, Causes and Risk Factors, New Delhi: Register General of India, 2006.

2. Hirve SS, Abortion law, policy and services in India: a critical review, Reproductive Health Matters, 2004, 12(24, Suppl.):114-121.

3. Duggal R and Ramachandran V, The abortion assessment projectIndia: key findings and recommendations, Reproductive Health Matters, 2004, 12(24, Suppl.):122-129.

4. Banerjee SK, Increasing Access to Safe Abortion Services in Uttarakhand: Identifying Medical Termination of Pregnancy Training Centers, New Delhi: Ipas India, 2007.

5. Bart Johnston H, Abortion Practice in India: A Review of Literature, Mumbai: Centre for Enquiry into Health and Allied Themes, 2002.

6. Banerjee SK and Tank J, Expanding the provider base: improving 
access, saving lives, in: Hathtootuwa $\mathrm{R}$ and Tank J, eds., Prevention of Unsafe Abortion in Asia Oceana Region, New Delhi: Impression Communications, 2009, pp. 93-103.

7. Ganatra B and Banerjee SK, Expanding Community-Based Access to Medical Abortion in Jharkhand: A Pre-Intervention Baseline Survey in Selected Two Blocks of Ranchi and Khunti Districts, New Delhi: Ipas India, 2010.

8. Pachauri S, Implementing a Reproductive Health Agenda in India: The Beginning, New Delhi: Population Council, 1999, pp. 507-529.

9. Piotrow PT et al., Health Communication: Lessons from Family Planning and Reproductive Health, Westport, CT, USA: Praeger, 1997.

10. Daniel EE, Masilamani R and Rahman M, The effect of communitybased reproductive health communication interventions on contraceptive use among young married couples in Bihar, India, International Family Planning Perspectives, 2008, 34(4):189-197.

11. United Nations Children's Fund, A critical leap to polio eradication in India, working paper, Kathmandu, Nepal: Regional Office for South Asia, 2003.

12. Sood S, Shefner-Rogers CL and Sengupta M, The impact of a mass media campaign on HIV/AIDS knowledge and behavior change in North India: results from a longitudinal study, Asian Journal of Communication, 2006, 16(3):231-250.

13. Rice RE and Atkin CK, eds., Public Communication Campaigns, third ed., Thousand Oaks, CA, USA: Sage, 2001.

14. Jejeebhoy SJ et al., Increasing Access to Safe Abortion in Rural Maharashtra: Outcomes of a Comprehensive Abortion Care Model, New Delhi: Population Council, 2011.

15. Banerjee SK et al., Involving health care intermediaries in providing information and referrals for medical abortion: a community-based intervention in Jharkhand, India, paper presented at the Global Maternal Health Conference, New Delhi, Sept. 1, 2010.

16. Baird TL, Billings DL and Demuyakor B, Community education efforts enhance postabortion care program in Ghana, American Journal of Public Health, 2000, 90(4):631-632.

17. Abroms LC and Maibach EW, The effectiveness of mass communication to change public behavior, Annual Review of Public Health, 2008, $29 \cdot 219-234$

18. Jato $\mathrm{M}$ et al., The impact of multimedia family planning promotion on the contraceptive behavior of women in Tanzania, International Family Planning Perspectives, 1999, 25(2):60-67.

19. Kim YM et al., Promoting sexual responsibility among young people in Zimbabwe, International Family Planning Perspectives, 2001, 27(1):11-19.

20. Babalola S, Ouedraogo D and Vondrasek C, Motivation for late sexual debut in Cote d'Ivoire and Burkina Faso: a positive deviance inquiry, Journal of HIV/AIDS Prevention $\mathcal{E}$ Education for Adolescents $\mathcal{E}$ Children, 2007, 7(2):65-87.

21. Goldstein S et al., Communicating HIV and AIDS, what works? A report on the impact evaluation of Soul City's fourth series, Journal of Health Communication, 2005, 10(5):465-483.

22. Banerjee SK et al., Woman-centered research on access to safe abortion services and implications for behavioral change communication interventions: a cross-sectional study of women in Bihar and Jharkhand, India, BMC Public Health, 2012, 12:175.

23. Bhushan S et al., Reducing maternal mortality in Madhya Pradesh by improved access to comprehensive abortion care services: learning of last five years, in: Seven Years of National Rural Health Mission (20052012) Madhya Pradesh Experience, Bhopal, India: National Rural Health Mission, 2012, pp. 47-49.

24. Banerjee SK, Andersen KL and Warvadekar J, Results of a Government and NGO Partnership for Provision of Safe Abortion Services in Uttarakhand, India, New Delhi: Ipas India, 2009

25. Gertler PJ et al., Impact Evaluation in Practice, Washington, DC: The World Bank, 2011.

26. Wooldridge JM, Introductory Econometrics: A Modern Approach, fourth ed., Mason, OH, USA: Cengage Learning, 2009, pp. 445-455.

\section{RESUMEN}

Contexto: Aunque el aborto se legalizó en la India en 1971, muchas mujeres desconocen la ley. Las intervenciones de comunicación para el cambio de comportamiento pueden ser una forma efectiva de promover el conocimiento de la ley y de cambiar los conocimientos y las percepciones acerca del aborto, especialmente en entornos en los que el aborto es objeto de estigma.

Métodos: Para evaluar la efectividad de una intervención de comunicación para el cambio de comportamiento dirigida a mejorar los conocimientos de las mujeres sobre la ley de aborto en la India y sus percepciones sobre el aborto, se llevó a cabo un estudio cuasi experimental en distritos de intervención y comparación en Bihary Jharkhand. Se administraron en 2008 encuestas a los hogares para crear una línea de base; para dar seguimiento, se administraron encuestas en 2010 a muestras independientes, transversales y seleccionadas aleatoriamente de mujeres del medio rural, casadas y en edades de 15-49 años. Se usó regresión logística con modelos de diferencias en diferencias para evaluar la efectividad del programa.

Resultados: Los análisis demostraron la efectividad del programa para mejorar los conocimientos y las percepciones sobre el aborto. Los cambios en las probabilidades de saber que el aborto es legal y dónde obtener servicios de aborto seguro fueron más grandes entre los datos de línea de base y los de seguimiento en los distritos de intervención, que el cambio en las probabilidades observadas en los distritos de comparación (cocientes de probabilidad, 16,1 y 1,9, respectivamente). De manera similar, el aumento en la percepción de las mujeres acerca de la existencia de un mayor apoyo social para el aborto dentro de sus familias, y el aumento en la autoeficacia percibida con respecto a la planificación familiar y el aborto entre los datos de línea de base y de seguimiento fueron mayores en los distritos de intervención que en los distritos de comparación (coeficientes, 0,17 y 0,18, respectivamente).

Conclusiones: Las intervenciones de comunicación para el cambio de comportamiento pueden ser efectivas para mejorar los conocimientos y las percepciones respecto al aborto en entornos donde la falta de conocimientos precisos limita el acceso de las mujeres a los servicios de aborto seguro. Deben usarse enfoques múltiples cuando se pretende mejorar los conocimientos y las percepciones acerca de temas de salud que son objeto de estigma, como es el caso del aborto.

\section{RÉSUMÉ}

Contexte: L'avortement a été légalisé en Inde en 1971, mais de nombreuses femmes restent ignorantes de la loi. Les interventions de communication pour le changement comportemental peuvent offrir un moyen efficace de sensibilisation à la loi et de transformation de la connaissance et des perceptions au sujet de l'avortement, en particulier dans les contextes où il reste stigmatisé.

Méthodes: Pour évaluer l'efficacité d'une intervention de communication pour le changement comportemental afin d'améliorer la connaissance des femmes concernant la loi de l'Inde sur l'avortement et leurs perceptions de la procédure, une étude quasi-expérimentale a été réalisée dans des districts 
d'intervention et de comparaison au Bihar et au Jharkhand. Des enquêtes de ménage ont été menées en 2008 (base) et 2010 (suivi) auprès d'échantillons transversaux aléatoires indépendants de femmes rurales mariées âgées de 15 à 49 ans. L'effcacité du programme a été évaluée au moyen de modèles de régression logistique en double différence.

Résultats: L'analyse a démontré l'efficacité du programme en termes d'amélioration de la connaissance et des perceptions relatives à l'avortement. Les chances de savoir que l'avortement est légal et où obtenir des services d'avortement sans risques ont changé davantage entre la base et le suivi dans les districts d'intervention par rapport à ceux de comparaison (OR, 16,1 et 1,9, respectivement). De même, l'augmentation de la perception féminine d'un plus grand soutien social de l'avortement au sein des familles et celle de l'auto-efficacité perçue concernant la planification familiale et l'avortement entre la base et le suivi se sont avérées supérieures dans les districts d'intervention (coefficients de 0,17 et 0,18, respectivement).

Conclusions: Les interventions de communication pour le changement comportemental peuvent jouer un rôle efficace dans l'amélioration de la connaissance et des perceptions concernant l'avortement dans les contextes où le manque de connaissances exactes entrave l'accès aux services d'avortement sans risques. De multiples approches doivent être adoptées dans les tentatives d'amélioration de la connaissance et des perceptions concernant les questions de santé stigmatisées telles que l'avortement.

\section{Acknowledgments}

The authors wish to thank The David and Lucile Packard Foundation for their support in implementing the comprehensive abortion care program in Bihar and Jharkhand.

Author contact: andersenk@ipas.org 